\title{
Review \\ Targeting histone deacetylase activity in rheumatoid arthritis and asthma as prototypes of inflammatory disease: should we keep our HATs on?
}

\author{
Aleksander M Grabiec, Paul P Tak and Kris A Reedquist
}

Division of Clinical Immunology and Rheumatology, Academic Medical Center, University of Amsterdam, Meibergdreef 9, 1105 AZ Amsterdam, The Netherlands

Corresponding author: Kris A Reedquist, k.a.reedquist@amc.uva.nl

Published: 17 October 2008

This article is online at http://arthritis-research.com/content/10/5/226

(c) 2008 BioMed Central Ltd

Arthritis Research \& Therapy 2008, 10:226 (doi:10.1186/ar2489)

\begin{abstract}
Cellular activation, proliferation and survival in chronic inflammatory diseases is regulated not only by engagement of signal transduction pathways that modulate transcription factors required for these processes, but also by epigenetic regulation of transcription factor access to gene promoter regions. Histone acetyl transferases coordinate the recruitment and activation of transcription factors with conformational changes in histones that allow gene promoter exposure. Histone deacetylases (HDACs) counteract histone acetyl transferase activity through the targeting of both histones as well as nonhistone signal transduction proteins important in inflammation. Numerous studies have indicated that depressed HDAC activity in patients with inflammatory airway diseases may contribute to local proinflammatory cytokine production and diminish patient responses to corticosteroid treatment. Recent observations that HDAC activity is depressed in rheumatoid arthritis patient synovial tissue have predicted that strategies restoring HDAC function may be therapeutic in this disease as well. Pharmacological inhibitors of HDAC activity, however, have demonstrated potent therapeutic effects in animal models of arthritis and other chronic inflammatory diseases. In the present review we assess and reconcile these outwardly paradoxical study results to provide a working model for how alterations in HDAC activity may contribute to pathology in rheumatoid arthritis, and highlight key questions to be answered in the preclinical evaluation of compounds modulating these enzymes.
\end{abstract}

\section{Introduction}

Persistent recruitment, activation, retention and survival of infiltrating immune cells in the synovium of patients with rheumatoid arthritis (RA) and other forms of inflammatory arthritis, stromal cell hyperplasia and eventual joint destruction, are fueled and maintained by a complex network of chemokines, cytokines, growth factors and cell-cell interactions. Explosive increases in our understanding of how distinct components of this network, such as TNF $\alpha$, IL-1, IL-6 and receptor activator of NFKB ligand, contribute to inflammation and joint destruction in RA have been translated into innovative and increasingly successful treatment of patients in the clinic [1]. Many of the extracellular stimuli driving pathology in RA do so through the activation of conserved intracellular signaling proteins and pathways, including NFKB, the mitogen-activated protein kinases, phosphatidylinositol 3 kinases (PI3Ks) and the Janus tyrosine kinase $(\mathrm{JAK}) /$ signal transducers and activators of transcription (STAT) pathway. These in turn represent additional targets for therapeutic intervention to which intensive academic, pharmaceutical and clinical effort is being applied [2]. The relative utilization, contribution and requirement of specific inflammatory mediators, and their intracellular signaling pathways, in the pathology of RA, however, is quite heterogeneous between patients - possibly explained by predisposing genetic factors and environmental influences [3].

Inflammatory gene responses are further subjected to epigenetic regulation, most simply defined as inherited or somatic modification of DNA that, rather than altering gene product function, changes gene expression without altering the sequence of bases in the DNA. Epigenetic modifications important to gene regulation include methylation of DNA and post-translational modification of histone proteins, which regulate the chromatin architecture and gene promoter access. Methylation of DNA, particularly of CpG dinucleotides clustered in islands surrounding gene promoter regions, can effectively silence gene expression by blocking transcription factor binding to DNA, or activating transcriptional co-repressors [4]. Changes in the methylation status of

$\mathrm{CBP}=\mathrm{cAMP}$ response element-binding protein-binding protein $\mathrm{COPD}=$ chronic obstructive pulmonary disease; FLS = fibroblast-like synoviocyte; FoxO = forkhead box class $\mathrm{O} ; \mathrm{GC}=$ glucocorticoid; $\mathrm{HAT}=$ histone acetyl transferase; $\mathrm{HDAC}=$ histone deacetylase; $\mathrm{HDAC} \mathrm{i}=$ histone deacetylase inhibitors; HIF- $1 \alpha=$ hypoxia-inducible factor 1 alpha; IFN = interferon; IL = interleukin; JAK = Janus tyrosine kinase; NF = nuclear factor; PI3K = phosphatidylinositol 3 kinase; PKB = protein kinase $\mathrm{B} ; \mathrm{RA}=$ rheumatoid arthritis; SAHA = suberoyl anilide bishydroxamide; STAT = signal transducers and activators of transcription; TNF $=$ tumor necrosis factor; TSA $=$ Trichostatin $A$. 
genes regulating cell proliferation, inflammatory responses and tissue remodeling have been reported in RA, systemic sclerosis and systemic lupus erythematosus, suggesting epigenetic contributions to pathology in these diseases [5,6]. Posttranslational modifications to histone proteins, including acetylation, methylation, phosphorylation, sumoylation and ubiquitination, regulate transcription factor access to gene-encoding regions of DNA and facilitate gene transcript elongation [7]. Recent evidence has suggested that decreased histone deacetylase (HDAC) activity in RA patient synovial tissue may relax the chromatin structure and promote pathology by enhancing transcription of inflammatory gene products [8].

Current discussion has focused primarily on possible epigenetic contributions of altered HDAC activity to the pathology of RA and other immune-mediated inflammatory diseases $[5,6,9]$. Little attention has been given, however, to the potential role of HDACs in nonepigenetic processes, such as the dynamic regulation of intracellular signaling pathways in RA. In the present review, we shall briefly introduce how reversible acetylation of histone and nonhistone proteins regulates gene expression, and how HDAC inhibitors (HDACi) influence this process, and we highlight key intracellular signal transduction pathways important to RA that are regulated by reversible acetylation. We will then critically review and reconcile paradoxical findings that, while depressed HDAC activity is thought to contribute to human immune-mediated inflammatory diseases, pharmacological inhibitors of HDAC activity display potent therapeutic effects in animal models of arthritis. In doing so, we provide a framework for assessing the role of HDACs in RA, and the therapeutic potential of modifying HDAC activity in the clinic.

\section{Regulation of gene expression by reversible acetylation}

Regulation of gene expression is directly associated with changes in the conformation of chromatin [10]. These changes occur as a result of acetylation and deacetylation of core histones, the major protein components of the chromatin structure $[10,11]$. Two copies of each of four histone proteins ( $\mathrm{H} 2 \mathrm{~A}, \mathrm{H} 2 \mathrm{~B}, \mathrm{H} 3$ and $\mathrm{H} 4)$ form a complex around which 146 base pairs of the DNA strand are wound. The $\mathrm{N}$-terminal tail of each histone contains several lysine residues, substrates for enzymatic modification by the addition of an acetyl group. Histone acetylation not only reduces the net positive charge of the protein, promoting DNA unwinding and relaxation of the chromatin structure, but also creates binding sites on the histone for transcriptional cofactors and other cellular proteins containing bromodomains [12]. Deacetylation of histone lysine residues reverses this process, allowing condensation of the nucleosome and preventing transcription factor and RNA polymerase II access to gene promoters $[7,10]$.

Reversible acetylation and deacetylation of histones is an important process in the regulation of inflammatory gene responses [11,13]. The acetylation status of histones is
Figure 1

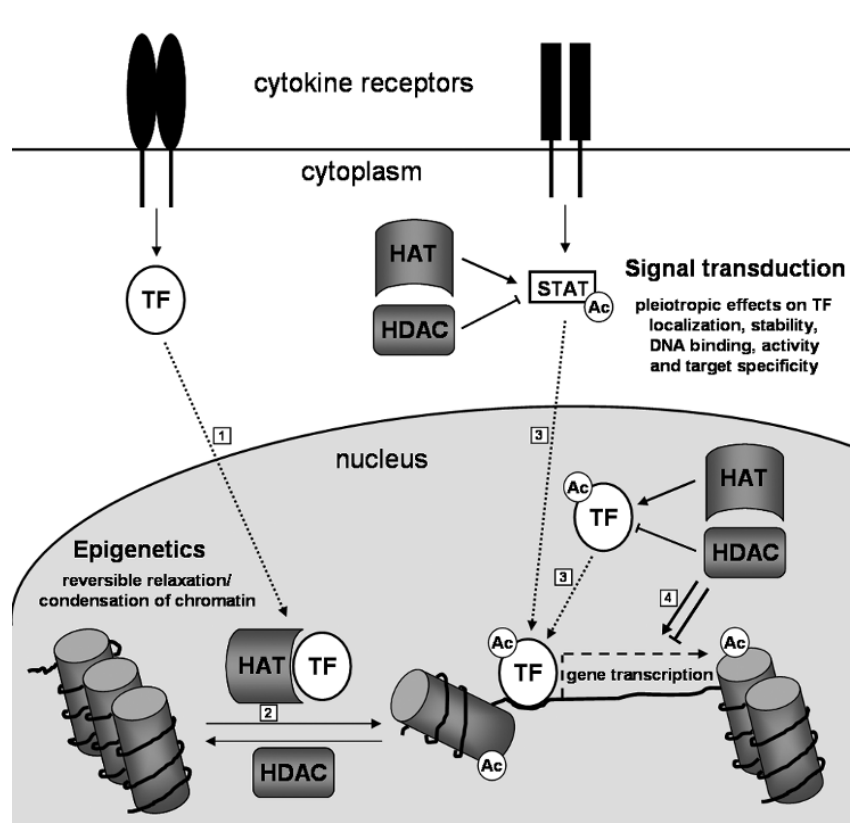

Epigenetic and signal transduction contributions of histone deacetylase activity to gene transcription and cell biology. (1) Ligation of cytokine or other inflammatory receptors leads to phosphorylation and/or dimerization of transcription factors (TF), followed by their nuclear translocation and association with histone acetyl transferases (HATs). (2) Subsequent activation of HATs contributes to epigenetic regulation of gene expression through acetylation (Ac) of histones (barrels), relaxing chromatin structure, and (3) exposing gene promoter regions to the TF. Histone deacetylases (HDACs) reverse this epigenetic process, leading to chromatin condensation and repression of gene expression. HATs and HDACs also finely tune gene expression and cellular processes through pleiotropic, nonepigenetic signaling pathways. Sequential acetylation and deacetylation of specific lysine residues on TF - such as signal transducers and activators of transcription (STAT), NFאB p65 and forkhead box class $\mathrm{O}$ proteins - in the nucleus or cytoplasm, influence TF protein stability, nuclear localization, DNA binding capacity, activation and gene target specificity. (4) Depending on the transcription factor and gene target, this can either enhance or inhibit gene transcription.

regulated by two different classes of enzymes: histone acetyl transferases (HATs) and HDACs. TNF $\alpha$, lipopolysaccharide and other inflammatory stimuli induce association of multiple transcription factors, including the NFKB p65/RelA subunit, activator protein 1, p53 and forkhead box class $\mathrm{O}$ (FoxO) proteins, with transcriptional coactivators containing intrinsic HAT activity (Figure 1) [14].

Transcription factor association with HATs, such as p300, cAMP-response element-binding protein-binding protein (CBP) or P/CAF, accomplishes three tasks important in the regulation of gene induction (Figure 1) [10]. First, transcription factor association with HATs targets HAT enzymatic activity to gene promoter regions. Second, the recruited HAT activity induces histone acetylation and exposure of gene promoter regions. Third, HATs acetylate the associated 
transcription factor - this can modify the protein half-life of the transcription factor, regulate its nuclear retention and modulate its transcriptional activity [11].

In the simplest of models, the enzymatic activity of HDACs opposes that of HATs, repressing gene transcription through deacetylation of histones, and repressing activation of transcription factors via deacetylation or recruitment of transcriptional co-repressors, such as glucocorticoid receptors $[11,15]$. For many transcription factors, however, including NFkB p65 and FoxO proteins, sequential acetylation and deacetylation of lysines on transcription factors is also required for stabilizing expression, or activating or determining the target gene specificity of the transcription factor (Figure 1) [14]. HATs and HDACs therefore do not function simply as on/off switches for gene transcription. Instead, a coordinated balance in their activity is required for the functional output of transcription factors.

\section{Histone deacetylases and histone deacetylase inhibitors}

The human genome encodes 18 different HDACs, which are grouped into four distinct classes based on structural homology with HDACs found in yeast [11,16]. Class I HDACs (HDAC1 to HDAC3 and HDAC8) are nuclear proteins broadly expressed throughout mammalian tissues and most closely resemble yeast RPD3. Class II HDACs (HDAC4 to HDAC7, HDAC9 and HDAC10), most similar to yeast HDA1, display a more restricted tissue expression and can shuttle between the nucleus and cytoplasm, exerting their effects on targets in both cellular compartments. HDAC11 is designated as the sole class IV HDAC, due to low sequence similarity with other HDACs [16]. Class III silent information regulator 2 (sirtuin) HDACs (Sirt1 to Sirt7) are nicotinamide adenosine dinucleotide-dependent enzymes, structurally unrelated to class I, class II and class IV HDACs. Of the sirtuins, only Sirt1 displays strong deacetylase activity, while the others have unknown functions or act as mono-ADP-ribosyl transferases. Sirt1, like other HDACs, targets both histone and nonhistone proteins $[17,18]$.

HDACi, both synthetic and naturally derived, can be grouped loosely into four categories based on their chemical structures [16,19]. Well-characterized hydroxamic acid derivatives include Trichostatin A (TSA), suberoyl anilide bishydroxamide (SAHA, vorinostat), and ITF2357. Butyrates and valproic acid are short-chain fatty acids, $\mathrm{HC}$-toxin and FK228 (depsipeptide, also known as FR901228 in earlier studies) are cyclic tetrapeptides/epoxides, and MS-275 is a benzamide derivative. In vitro these compounds inhibit HDAC activity at concentrations ranging from nanomolar (TSA, ITF2357, HC-toxin) to millimolar (butyrates, valproic acid). The hydroxamates are nonspecific in the sense that they do not discriminate between distinct class I, class II and class IV HDACs. In contrast, valproic acid and MS-275 selectively target class I HDACs at lower concentrations, while also inhibiting class II HDACs at higher concentrations $[16,19,20]$. Knowledge of the crystal structure of HDACi bound to HDACs, as well as the development of strategies allowing high-throughput analysis of chemical libraries, is leading to the generation of new HDACi and the potential identification of HDAC isoform-specific inhibitors. One novel compound identified by this strategy is tubacin, a specific inhibitor of HDAC6 [21]. Sirtuins, as well as other nicotinamide adenosine dinucleotide-dependent enzymes, are inhibited by nicotinamide. A growing list of sirtuin inhibitors, including sirtinol, is being identified through biochemical screens [22], but their influence on cellular biology or gene responses relevant to inflammatory disease is just beginning to be assessed [23].

Many of the compounds listed above are in phase I, phase II and phase III clinical trials for the treatment of leukemias and solid tumors $[16,19,20,24]$. In general, cancer cells are more sensitive to HDACi than their nontransformed cellular counterparts, these compounds have been well tolerated by patients, and therapeutic effects have been documented. Most HDACi have been shown to induce cell cycle arrest, differentiation and/or apoptosis in a wide range of transformed cells in vitro, in animal tumor models and in clinical cancer trials [19]. The ability of HDACi to induce tumor growth arrest is predominantly associated with their ability to induce expression of cyclin-dependent kinase inhibitor p21Waf1. Apoptosis induction may be secondary to cell cycle arrest, or may be a result of cell-specific regulation of proapoptotic genes (Bak, Bax, Bim, Noxa, Puma and TRAIL) and of antiapoptotic genes (IAPs, Mcl-1, Bcl-2, $\mathrm{Bcl}-\mathrm{XL}$, and FLIP) $[25,26]$.

\section{Nonhistone targets of histone deacetylases in RA}

Several lines of experimental evidence make it increasingly clear that the effects of $\mathrm{HDACi}$ on cellular activation, proliferation and survival cannot be attributed solely to the regulation of chromatin structure.

First, in cancer trials it has been difficult to establish a clear association between HDACi pharmacokinetics and histone acetylation $[27,28]$. Second, gene array profiles obtained from cell lines exposed to different HDACi report that only $2 \%$ to $10 \%$ of expressed genes are regulated by $\mathrm{HDACi}$, a comparable number of which are upregulated and are downregulated $[26,29,30]$. These findings are generally incompatible with global chromatin opening being the primary effect of HDACi exposure. Third, careful analysis of cellular dose-responsiveness to HDACi has demonstrated regulation of cytokine production in the absence of changes in histone acetylation status [31]. Fourth, phylogenetic studies in bacteria indicate that HDACs evolved prior to histones, suggesting an initial role for HDACs in the regulation of nonhistone substrates [32]. Fifth, a number of gene product targets used as biomarkers for HDACi activity in vivo, such as 
p21 Waf1, are also regulated by transcription factors that are direct substrates of HDACs. The acetylation status of these transcription factors influences protein stability, activation and gene promoter specificity.

Some 200 nonhistone proteins have been identified as HDAC substrates, at least in vitro [14,19], and a subset of these substrates has already been identified as playing an important role in disease perpetuation and progression in RA [2]. Studies addressing the acetylation status of signaling proteins, and consequences of changes in protein acetylation for cellular activation and survival in RA synovial tissue, may define how depressed HDAC activity contributes to pathology in RA, and may suggest molecular mechanisms responsible for the therapeutic effects of HDACi in animal models of arthritis.

\section{Regulation of NFKB signaling}

Components of the NFKB transcription factor are highly expressed and activated in RA synovial tissue, making significant contributions to inflammatory gene expression and cellular survival in the synovium [2]. The NFKB p65/RelA subunit is acetylated on at least five distinct lysine residues by $\mathrm{p} 300 / \mathrm{CBP}$. Acetylation of lysine 221 weakens p65 affinity for $1 \kappa B \alpha$, allowing dissociation of p65 and subsequent nuclear import [33]. This acetylation step also enhances p65 affinity for DNA, but a separate acetylation event at lysine 310 is required to enhance p65 transcriptional activity [34]. Acetylation of p65 at distal lysines 122 and 123 reciprocally decreases the p65 binding affinity to DNA, enhances association with $I \kappa \mathrm{B} \alpha$, and promotes nuclear export of the transcription factor [35]. HDAC1, HDAC2 and HDAC3 can promote deacetylation of p65 at lysine 221, stabilizing p65- $1 \kappa B \alpha$ interactions [33], while SIRT1 can inactivate p65 through deacetylation of lysine 310 [36].

\section{Regulation of FoxO signaling}

The human FoxO family of transcription factors consists of four members: FoxO1, FoxO3a, FoxO4 and FoxO6. The PI3Kresponsive $\mathrm{FoxO} 1$, FoxO3a and $\mathrm{FoxO} 4$ proteins modulate the expression of genes regulating cell cycling (for example, $\mathrm{p} 27^{K i p 1}$ and $\mathrm{p} 21^{\text {Waf1}}$ ), genes regulating stress responses (for example, catalase and manganese superoxide dismutase) and genes regulating apoptosis (for example, FasL, Bim, and TRAIL) [37].

FoxO proteins integrate growth factor and stress stimuli either to promote cell proliferation, growth arrest and survival or to induce apoptosis [38]. Activation of the PI3K/protein kinase $B(P K B)$ pathway by growth factors and inflammatory cytokines results in FoxO phosphorylation, subsequent nuclear exclusion and a block in transcription of FoxOregulated genes. PI3K/PKB signaling is highly activated in RA synovial tissue, and significantly elevated levels of PKBinactivated FoxO4 are present in RA synovial tissue macrophages compared with disease controls $[39,40]$. Curiously, within RA patient populations, PKB-dependent inactivation of FoxO1, FoxO3a and FoxO4 correlates inversely with patient parameters of inflammatory disease activity (erythrocyte sedimentation rate and serum C-reactive protein concentrations) [40]. This might be explained by findings that oxidative stress and proinflammatory cytokines counteract PI3K/PKB signaling to drive nuclear localization, transcriptional activation and gene target specificity of FoxO proteins [38].

JNK-dependent phosphorylation of FoxO proteins, possibly in conjunction with Mst-1-dependent phosphorylation, promotes FoxO nuclear import [38]. In the nucleus, FoxO proteins can undergo serial acetylation and deacetylation. Although details are still emerging, it appears that acetylation of FoxO proteins by $\mathrm{p} 300 / \mathrm{CBP}$ can induce transcription of proapoptotic gene products or, in the presence of sufficient PI3K/PKB signal, facilitate FoxO nuclear export [41]. Sequential deacetylation events mediated by class I/II HDACs and Sirt1, however, target FoxO to transcribe genes needed for cell cycle arrest and survival responses to environmental stress [38].

The ability of FoxO transcription factors to integrate multiple signals to determine cell fate choices (proliferation, survival or apoptosis) influencing inflammatory disease in vivo is strikingly recapitulated in FoxO3a-deficient mice. Mice lacking FoxO3a develop spontaneous systemic autoimmune disease marked by proliferation and activation of autoimmune $\mathrm{T}$ cells [42]. When these mice are crossed onto a Rag2 ${ }^{-/}$ background (lacking lymphocytes), however, the resulting progeny are resistant to $\mathrm{K} / \mathrm{BxN}$ serum-induced arthritis, probably due to Fas-induced apoptosis of activated neutrophils [43]. Together, these studies provide circumstantial evidence that FoxO proteins interpret contextual signals to regulate inflammatory responses in vivo.

\section{Regulation of tumor suppressor p53 signaling}

The tumor suppressor protein p53 regulates cellular responses to stress signals causing DNA damage. Stabilization and transcriptional activation of p53 induces cell cycle arrest at the $G_{1} / S$ interface, allowing for effective repair of fragmented DNA. When the extent of DNA damage is broad, cells undergo p53-induced apoptosis [2].

In RA, high levels of fragmented DNA are detected in synovial tissue, and increased protein expression of p53 is often observed, primarily in late stages of the disease [44]. The enhanced protein expression of p53 might be explained by reactive oxygen species-induced somatic mutations in p53 [45]. Some of these mutations lead to the expression and accumulation of inactive p53, which could in turn contribute to inadequate apoptotic responses of stromal cells in the inflamed joint [46]. The p53 protein half-life and activation, however, is tightly regulated by multiple reversible phosphorylation, methylation, ubiquination and acetylation events, which could also contribute to altered p53 protein expression and function in RA synovial tissue [47]. 
Acetylation of $\mathrm{p} 53$ by $\mathrm{p} 300 / \mathrm{CBP}$ or P/CAF can increase p53 protein stability in vitro, by blocking Mdm2-mediated ubiquitination and proteasomal degradation of p53. Acetylation of p53 is reversed by Sirt1, inhibiting p53 transcriptional activity and facilitating its degradation [48]. Association of p53 with HATs can also result in transactivation of p53, although additional mutational and genetic studies have cast doubt on how and whether acetylation regulates p53 stability or activity in vivo [47]. Given the potent effects of p53 on fibroblast-like synoviocyte (FLS) proliferation and survival in vitro, it will be of interest to determine whether acetylation also regulates the function of p53 in RA synovial tissue.

\section{Regulation of JAK/STAT signaling pathways}

Activation of JAK kinases and subsequent stimulation of transcriptional activity of the STAT family of transcription factors is one of the main signaling pathways triggered by cytokines. JAK/STAT signaling regulates expression of genes involved in cellular activation, differentiation and survival [2]. In analyses of RA synovial tissue, increased expression and activation of STAT1 is observed in RA patients compared with disease control individuals [49]. Additionally, activation of STAT3 contributes to the survival of RA synovial macrophages. Inhibition of STAT3 induces apoptosis in macrophages isolated from the joints of RA patients via downregulation of the antiapoptotic protein Mcl-1 [50].

The regulation of gene expression by STATs requires HDAC activity - TSA, SAHA and butyrate can block activation of JAK1 and subsequent STAT1 phosphorylation in IFN $\gamma$ stimulated carcinoma cells, and STAT1-dependent transcription can be enhanced by overexpression of HDAC1, HDAC2 or HDAC3 [51]. Also, the protective effects of SAHA in a murine model of graft versus host disease are associated with a block in the rapid accumulation of phosphorylated STAT1 in the liver and the spleen [52]. While it appears that acetylation may regulate STAT1 signaling indirectly, substantial evidence indicates that STAT3 is a direct target of HATs and HDACs. STAT3 dimerization, DNA binding and transcriptional activation following cytokine stimulation requires p300/CBP-induced acetylation, and can be negatively regulated by overexpression of HDACs - primarily HDAC3 $[53,54]$.

It is thus clear that reversible acetylation and deacetylation play a central role in the function of intracellular signaling proteins that regulate cellular activation and cytokine production, proliferation and survival - key cellular themes in the maintenance of chronic inflammation. As many of the signaling proteins discussed above are known (or highly suspected) to contribute to pathology in RA, it will be of interest to determine the acetylation status of these proteins in RA synovial tissue, and how modulation of HDAC activity regulates signaling capacity. Given the pleiotropic effects that acetylation can confer upon transcription factor function, as evident with NFKB p65 and FoxO proteins, it will be critical to distinguish between effects on DNA binding capacity, transcriptional activity and gene target specificity.

\section{Acetylation in human immune-mediated inflammatory disease}

The most detailed analyses of how alterations in HAT and HDAC activity, and consequent epigenetic or signaling effects, might contribute to chronic immune-mediated inflammatory diseases are found in studies of human airway diseases, such as asthma and chronic obstructive pulmonary disease (COPD). In both bronchial biopsies and alveolar macrophages isolated from asthma patients, a significant increase in HAT activity is detected [55,56]. A selective decrease in HDAC1 expression is also observed in asthma alveolar macrophages, corresponding with a decrease in cellular HDAC activity. Decreased HDAC activity is in turn associated with enhanced alveolar macrophage production of proinflammatory granulocyte-macrophage colony-stimulating factor, TNF $\alpha$ and IL-8 in response to lipopolysaccharide. Similar changes in HAT and HDAC activity are not observed in peripheral blood mononuclear cells from the same patients, suggesting that alterations in reversible acetylation are restricted locally to the site of inflammation [55].

In COPD patients, enhanced bronchial biopsy and alveolar macrophage HAT activity does not occur, but a significant reduction in total HDAC activity, and gene expression of HDAC2, HDAC5 and HDAC8 but not of other class I/II HDACs, is observed. The degree of local HDAC impairment in COPD patients correlates with histone acetylation, IL-8 production and disease severity [57].

Evidence has also been provided that altered expression of class III HDACs may contribute to chronic inflammation in COPD. SIRT1 expression is decreased at both the mRNA and protein levels in COPD bronchial biopsies and alveolar macrophages. Oxidative stress may contribute to decreased SIRT1 protein expression in COPD, as enhanced carbonylation and tyrosine nitration of SIRT1, mimicked by exposure of SIRT1 to cigarette smoke extract, is observed [58]. A potential role for sirtuins in autoimmunity is further suggested by the observation that aged mice lacking the sirt 1 gene display deposition of autoimmune $\lg _{1}$ antibodies in their liver and kidneys, and show symptoms of diabetes insipidus [59].

Initial reports indicate that alterations in the balance of HAT and HDAC activity may also contribute to perpetuation of inflammation in RA. In a small study examining synovial tissue obtained during joint replacement surgery of seven RA patients, six osteoarthritis patients and control subjects, no differences in HAT activity were observed [8]. HDAC activity and the ratio of HDAC/HAT activity, however, were significantly depressed in RA synovial tissue compared with tissue from osteoarthritis patients and control patients. Protein expression of HDAC1 and HDAC2 in whole synovial tissue was lower in RA patients compared with osteoarthritis 
(a)

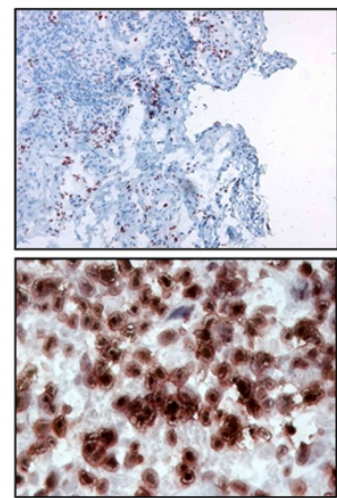

(b)

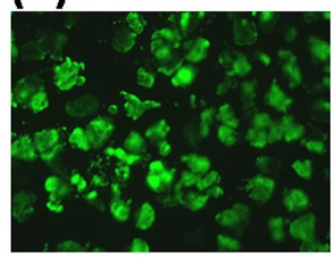

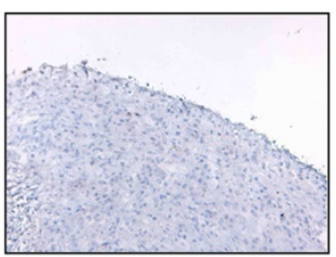
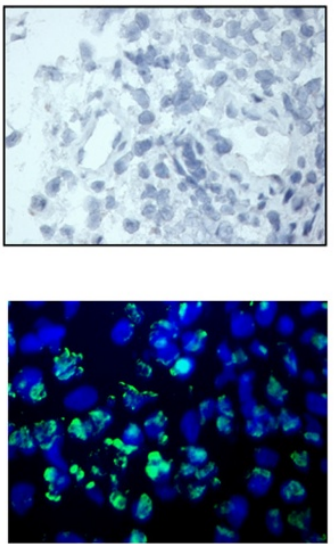

(c)

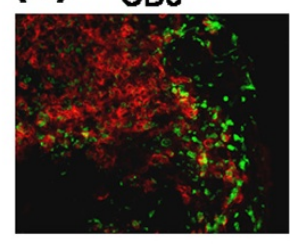

CD55
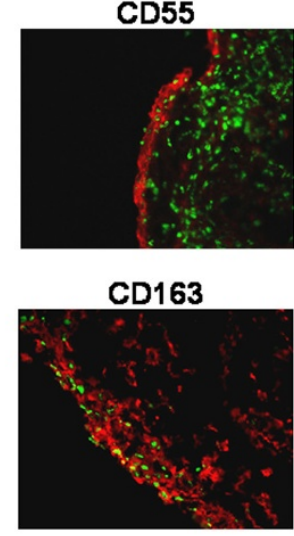

CD22

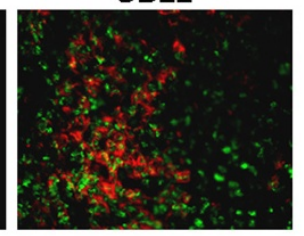

CD68

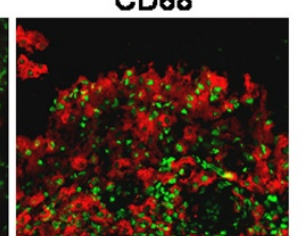

control

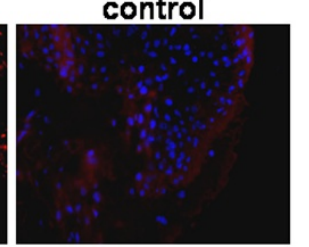

(d)

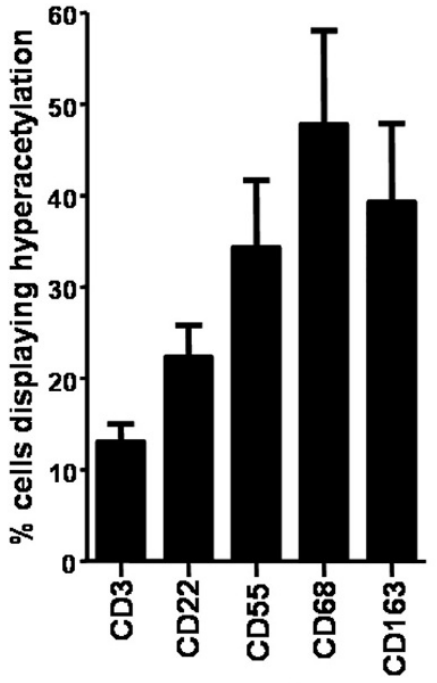

cell marker

Hyperacetylation of cellular proteins in rheumatoid arthritis synovial tissue. (a) Immunohistochemical staining of rheumatoid arthritis (RA) synovial tissue with antibodies against acetyl-lysine (Ac) (upper panels) and control rabbit antibodies (lower panels): 100x (left panels) and 400x (right panels) magnifications are displayed. (b) Immunofluorescent staining of RA synovial tissue (400x magnification) with anti-Ac antibodies (green) alone (upper panel) or in combination with 4',6-diamidino-2-phenylindole dihydrochloride staining (blue) (lower panel) showing localization to cellular nuclei. (c) Representative immunofluorescent double staining of RA synovial tissue with anti-Ac antibodies (green) and antibodies against cellular markers (red) for T lymphocytes (CD3), B lymphocytes (CD22), fibroblast-like synoviocytes (CD55), or synovial macrophages (CD68 and CD163). (d) Quantification of protein hyperacetylation in specific synovial cellular subsets. Double stainings were performed on RA synovial tissue and a minimum of 100 random cells positive for each CD marker assessed for hyperacetylation of nuclear proteins. Values represent the mean percentage and standard error of the mean of cells positive for each marker displaying protein hyperacetylation from four RA patients. Samples were obtained from patients fulfilling the American College of Rheumatology criteria for RA [98]. Detailed descriptions of materials and methods used in these experiments have either been described elsewhere [60] or are available in Additional file 1.

patients, and immunohistochemical staining revealed a marked decrease in HDAC2 protein expression in RA compared with osteoarthritis, particularly in synovial macrophages. These results led the authors to two conclusions with important ramifications for future studies.

First, the data suggest an association between pathogenic inflammatory processes in the RA synovium and reductions in HDAC activity [8]. It is still uncertain whether the noted changes in HDAC activity in RA synovial tissue are sufficient to result in enhanced acetylation of histones or nonhistone proteins, but - consistent with this possibility - we have noted in a small study of four RA patients that acetylation of cellular proteins in RA synovial tissue is most readily detected within infiltrating macrophages (Figure 2). Within RA synovial tissue, faint staining by anti-acetyl lysine antibodies is detected throughout the tissue (Figure 2a), consistent with a universal physiological role for histone and nonhistone protein acetylation in regulating gene transcription and other cellular activities. In a subset of cells, however, strong hyperacetylation is observed, localized to the nucleus (Figure 2a,b).
Doublestaining experiments performed on a small set of RA patients suggest that this occurs most frequently in synovial macrophages $\left(\mathrm{CD}^{+} 8^{+}, 48 \pm 10 \%\right.$; $\left.\mathrm{CD}^{2} 3^{+}, 39 \pm 9 \%\right)$, the same cell population within RA synovial tissue in which depressed HDAC2 expression has been reported [8]. We also frequently observe protein hyperacetylation in RA stromal FLS ( $35 \pm 7 \%$ ), but rarely in synovial B lymphocytes (22 $\pm 3 \%)$ and $\mathrm{T}$ lymphocytes (12 $\pm 2 \%)$. A pressing question that remains to be determined experimentally is whether these differences in HDAC activity and protein acetylation can promote inflammatory gene transcription in RA.

A second important prediction put forth by Huber and colleagues is that the observed decrease in HDAC activity and expression in RA synovial tissue might preclude the therapeutic application of HDACi in RA [8]. Important to this is their observation that total HDAC activity is decreased by approximately $75 \%$ in RA compared with normal synovial tissue. One caveat to this interpretation of the data is that the HDAC activity measured in this study was not normalized for tissue cellularity or cell-type composition of the tissue. A 
second caveat is that the tissue assessed was obtained from patients at the time of joint replacement. Important differences in synovial cellular composition and cytokine profiles have been detected between arthroscopic biopsies of RA patients with active disease and specimens obtained during joint replacement [60], underscoring the need for follow-up studies of HDAC expression and activity in RA patients representative of those who would be participating in clinical trials.

If the initial study results of Huber and colleagues can be extended to active RA, this would certainly suggest that the total availability of HDACs for inhibitory compounds would be reduced. As yet, however, it is unclear whether HDAC1 and HDAC2, reduced in RA, would be the relevant targets responsible for potential anti-inflammatory effects of $\mathrm{HDACi}$, and whether the residual total HDAC activity present in RA synovial tissue might still play an essential role in cellular activation and survival. These unknown factors necessitate extensive formal studies.

\section{Histone deacetylases and glucocorticoid treatment}

Glucocorticoids (GCs) are invaluable therapeutic tools in the treatment of many chronic inflammatory diseases, including asthma and RA. Recent findings in the study of inflammatory lung diseases demonstrate that HAT activity and HDAC activity significantly impact upon the clinical efficacy of GC therapy [15]. GC receptor-binding to $\mathrm{GC}$ response elements in gene promoter regions can directly regulate gene transcription, while at lower concentrations, GC also induce GC receptor association with, and functional inhibition of, transcription factors such as NFKB and activator protein 1.

GC-induced reduction of inflammatory gene transcription in asthma patients is associated with the enhancement of HAT activity and with the recruitment of HDAC2 to activated NFKB complexes $[55,61]$. In contrast to asthma patients, patients with COPD are relatively resistant to GC therapy, and this could be in part due to depressed HDAC2 expression and activity [15,57]. Although HDAC2-deficiency does not affect nuclear import or GC response element binding of $\mathrm{GC}$ receptors, HDAC2-dependent deacetylation of $\mathrm{GC}$ receptors is required for their association with NFKB. The anti-inflammatory capacity of GC in asthma and COPD alveolar macrophages can be restored either by overexpression of HDAC2 or by theophylline-induced enhancement of HDAC activity, indicating that strategies aimed at restoring HDAC activity may enhance the efficacy of GC therapy $[55,62]$.

$\mathrm{GC}$ resistance in the treatment of $\mathrm{RA}$ is not as clearly defined as in COPD [63]. More than 30\% of RA patients, however, have been estimated to demonstrate a decrease in responsiveness to GC therapy within 3 to 6 months from initiation of treatment [64]. The reasons for this are currently unknown. Suggested possibilities include decreased expression of GC receptors, or changes in expression levels of chaperone and co-chaperone proteins needed for GC receptor folding and stability. Alternative contributions might be made by increased expression of inflammatory transcription factors, expression of alternatively spliced decoy GC receptors, and upregulation of the multidrug resistance gene MDR1 [63]. In analogy to COPD, we should consider whether depressed HDAC2 expression and activity in RA could also contribute to variation in patient responses to $\mathrm{GC}$ treatment. If this possibility was to be substantiated, it would have two important clinical implications. First, restoration of HDAC activity might increase patient responsiveness to GC treatment, or might allow effective utilization of lower doses of GC. Second, future clinical trials specifically targeting HAT or HDAC activity to treat RA would need to be conducted in the absence of concomitant GC treatment, as effects of HAT/HDAC modulators on $\mathrm{GC}$ responsiveness might introduce a significant confounding factor to analyses of the studies.

In vitro, depsipeptide HDACi can induce upregulation of MDR1 and its gene product P-glycoprotein in cancer cell lines, conferring resistance to $\mathrm{GC}$ and chemotherapeutic drugs $[65,66]$. Curiously, interactions between HDACi and the chemotherapeutic compound doxorubicin appear to be extremely sensitive to the sequence of drug administration. Pretreatment of cells with HDACi reduces subsequent doxorubicin-induced apoptosis, while pretreatment with doxorubicin sensitizes cells for HDACi-induced apoptosis. Given the potential importance of these drug interactions in future clinical trials, significant efforts need to be devoted to this issue in preclinical analysis of HAT and HDAC modulators.

\section{Histone deacetylase inhibitors in animal models of inflammatory disease}

While the studies above suggest that strategies aimed at increasing HDAC activity could have therapeutic benefit in $\mathrm{RA}$, other lines of experimental analysis have instead provided evidence that inhibition of HDAC activity should be pursued. Early observations that HDACi could not only induce cell cycle arrest and apoptosis in cancer cell lines, but also block inflammatory cytokine production in these cells, provided a rationale for experiments examining whether HDACi could be used therapeutically to treat immune-mediated inflammatory diseases. Compounds representing each of the chemical classes of HDACi have been used successfully in prophylactic and therapeutic protocols in multiple animal disease models, including those for asthma, systemic endotoxic shock, colitis, lupus, multiple sclerosis and graft versus host disease $[67,68]$.

A broad spectrum of HDACi has also shown potent prophylactic and therapeutic effects in animal models of arthritis. The first application of HDACi to the treatment of arthritis was reported by Chung and colleagues [69]. Topical ointments of phenylbutyrate and TSA were applied to rat paws prior to induction of adjuvant-induced arthritis. Although 
neither compound prevented arthritis onset, both compounds inhibited paw swelling of treated paws, compared with untreated and contralateral paws. Synovial inflammatory infiltration, pannus formation and bone erosion were also significantly reduced. The prophylactic effects of both phenylbutyrate and TSA were associated with local accumulation of acetylated histone proteins in the tissue, an increase in expression of the cell cycle inhibitors p16 $6^{\text {Ink } 4}$ and p21Waf1, and depressed TNF $\alpha$ synthesis. Notably, HDACi treatment of nonarthritic rats did not induce cell cycle inhibitor expression, suggesting these compounds may preferentially affect cells in the local inflammatory environment.

Another HDACi, the depsipeptide FK228, has displayed both prophylactic and therapeutic benefits in rat adjuvant-induced arthritis when administered intravenously [70]. Prophylactic administration of the compound significantly reduced paw swelling and completely blocked the development of bone erosions. Although administration of FK228 after the onset of arthritis failed to reduce paw swelling in this model, bone erosion scores were reduced by almost $70 \%$. FK228 was also tested in the murine autoantibody-mediated model of arthritis. A single-dose systemic administration of FK228, administered after the clinical onset of arthritis, significantly reduced joint swelling, synovial inflammation and bone erosion [71]. The clinical benefits of FK228 were again mirrored by an increase in synovial cell histone acetylation, induction of synovial p16/nk4 and p21Waf1 expression, and decreased TNF $\alpha$ synthesis.

SAHA and MS-275 have been examined in murine and rat collagen-induced models of arthritis [72]. In mice, daily subcutaneous injection of SAHA led to moderate dosedependent reductions in paw swelling, and production of IL-6 and IL-1 $\beta$, but minimally reduced synovial infiltration and bone destruction. MS-275, in contrast, provided almost complete protection against arthritis, as assessed by the same parameters. In rats, both SAHA and MS-275 effectively reduced arthritis severity and bone erosion, although MS-275 was again more effective. When administered therapeutically in rats, MS-275 prevented both a further increase in paw inflammation, as well as the onset of bone erosions.

These studies together indicate that HDACi, irrespective of their chemical classification, have the potential to alleviate inflammation and to prevent joint destruction in arthritis. Of particular interest to the clinical setting is the finding that a subset of these compounds may be therapeutically useful in established arthritis.

\section{Effects of histone deacetylase inhibitors on RA synovial cells}

Attempts to extrapolate to RA the therapeutic benefits of HDACi in animal models of arthritis, or the potential advantages of enhancing HDAC activity, will require a thorough analysis of the effects of HAT and HDAC modulation on primary human immune and stromal cells relevant to RA, preferably those derived from RA synovial tissue. As yet, there is only a limited number of studies published assessing a few of the cell populations considered important to the pathology of RA.

\section{T lymphocytes}

Initial studies in T-cell responses indicate that HDAC inhibition can reduce the activation of pathogenic effector $T$ cells and of memory $T$ cells, while enhancing regulatory T-cell function. Incubation of healthy donor peripheral blood mononuclear cells with TSA reduces phytohemagglutinin and toxic shock syndrome toxin 1 -induced production of T-helper type 1 cytokines, such as IFN $\gamma$, while enhancing T-helper type 2 cytokine production [73]. TSA similarly normalizes T-helper type 1-skewed cytokine production in mitogen-stimulated T cells from systemic lupus erythematosus patients [74]. However, SAHA, another HDACi, is ineffective in blocking anti-CD3-induced human T-cell IFN $\gamma$ production, as well as in vitro and in vivo alloantigen-driven murine T-cell activation and proliferation $[52,75]$.

Intriguing evidence has recently emerged that HDAC activity can also modulate the generation and function of antiinflammatory thymic-derived natural regulatory $T$ lymphocytes [76]. Systemic treatment of mice with TSA increases the frequency of natural regulatory $T$ cells. Either incubated with TSA in vitro or isolated from TSA-treated mice, regulatory $T$ cells display elevated FoxP3 expression and have enhanced suppressive function in vitro. FoxP3 is acetylated under these conditions, promoting FoxP3 association with the $I L-2$ promoter. HDAC9, prominently expressed in regulatory T cells, appears to be responsible for inactivating FoxP3, and regulatory $\mathrm{T}$ cells from HDAC9 knockout mice are increased in numbers and suppressive capacity [76]. It is as yet unclear whether human regulatory $T$ cells are similarly regulated by HDAC9 activity, but together these studies suggest that HDACi effects on T-cell-dependent immune responses are dependent upon the mode of T-cell activation, T-cell differentiation status or lineage commitment, and on the HDACi used.

\section{Monocytes}

HDACi have been most extensively studied in monocytes and monocyte-derived cell lineages. SAHA inhibits release of TNF $\alpha$, IL-1 $\beta$, IL-12 and IFN $\gamma$ by lipopolysaccharide-stimulated human monocytes [75]. The anti-inflammatory effects of SAHA are selective, as IL- 8 production remains unaffected. Moreover, while induction of TNF $\alpha, \quad \mathrm{IL}-12$ and IFN $\gamma$ production is inhibited at the transcriptional level, defects in $\mathrm{IL}-1 \beta$ release are due to blocks in cytokine exocytosis [31].

The effects of SAHA on monocyte cytokine production and release are mimicked by other class I/II HDACi (TSA and ITF2357), the class I-selective HDACi HC-toxin, and the HDAC6-specific HDACi tubacin [31]. In all cases, HDACi 
blocked cytokine production at concentrations insufficient to cause monocyte apoptosis, providing evidence that antiinflammatory effects of HDACi can be achieved in the absence of general cellular toxicity. Murine bone marrowderived monocyte differentiation into macrophages is unaffected by HDACi, but these compounds suppress differentiation into osteoclasts [77]. In vitro, this may be a result of inhibition of receptor activator of NFKB ligand-induced NFKB transcriptional activity; and in vivo, via induction of IFN $\beta$ production by synovial cells [70].

\section{Macrophages and dendritic cells}

Studies of asthma and COPD alveolar macrophages demonstrating that decreased HDAC expression and activity are associated with enhanced lipopolysaccharide-induced granulocytemacrophage colony-stimulating factor, TNF $\alpha$ and IL-8 release might predict that HDACi would also enhance macrophage inflammatory responses $[55,57]$. While HDACi block restoration of alveolar macrophage GC responsiveness induced by theophylline or HDAC overexpression [62,78], experiments directly examining the influence of $\mathrm{HDACi}$ on asthma and COPD alveolar macrophage activation have not been reported. In contrast, the pan-HDACi LAQ824 selectively inhibits monocyte-derived macrophage and dendritic cell production of monocyte/macrophage/dendritic cell chemokines and chemokine receptors, as well as the production of costimulatory molecules, cytokines and chemokines required for T-helper type 1 T-cell recruitment and activation [79].

\section{Fibroblast-like synoviocytes}

Stromal FLSs are the only cell population isolated from RA synovial tissue in which the effects of HDACi have been studied. Incubation of RA FLS with FK228 induces cell cycle arrest, associated with enhanced expression of the cell cycle inhibitor $\mathrm{p} 16^{\text {Ink4a }}$ and acetylation of the $\mathrm{p} 16^{\text {Ink4a }}$ promoter region [71]. Treatment of FLS with either FK228 or TSA fails to induce apoptosis, but TSA can sensitize FLS to TRAILinduced apoptosis $[71,80]$. This suggests that HDACi might be particularly effective in targeting FLS proliferation or survival at the site of inflammation. Supporting this, while TSA and phenylbutyrate induce cell cycle arrest in FLS obtained from healthy rats and arthritic rats, cell cycle arrest is reversible in normal FLS following drug removal, but maintained in FLS derived from arthritic joints [69].

It will be of interest to examine the effects of HDACi on FLS cytokine production, as these compounds have demonstrated both inflammatory and therapeutic effects on (model stromal cells or) stromal cells derived from other immune-mediated inflammatory diseases. In SV-40-transformed bronchial epithelial cell lines - often used as models in asthma and COPD studies - TSA alone, or in synergy with oxidative stress, can induce IL-8 production [81]. In fibroblasts obtained from biopsies of patients with systemic sclerosis, TSA reduces transforming growth factor beta, IL-4 and platelet-derived growth factor-induced collagen synthesis [82].

\section{Endothelial cells and angiogenesis}

Angiogenesis in the synovial membrane contributes to synovitis and disease progression in RA by increasing inflammatory white blood cell access to affected joints, sustaining the nutritional requirements of invasive hyperplastic synovial tissue and stimulating osteoclast-mediated bone resorption [83]. A potential role for HDACs in regulating angiogenesis in chronic inflammatory diseases has not been addressed experimentally, but can be predicted based on numerous studies from tumor biology and the characterization of genetically modified mice.

HDACi display inhibitory effects on angiogenesis in both in vitro and in vivo tumor models [84-90]. These effects probably result from both epigenetic influences and acetylation of hypoxia-inducible factor 1 alpha $(\mathrm{HIF}-1 \alpha)$ - acetylation of HIF- $1 \alpha$ promotes ubiquitination and degradation of this critical transcriptional regulator of proangiogenic and antiangiogenic factors $[86,87,91]$. In these tumor models, class II HDACs - rather than class I HDACs - appear to coordinate angiogenesis. In human renal carcinoma cells, inhibition of class I HDAC activity is insufficient to suppress HIF- $1 \alpha$, but silencing of class II HDAC4 and HDAC6 can induce HIF- $1 \alpha$ acetylation, reducing both HIF- $1 \alpha$ expression and activity [87].

Cellular and molecular mechanisms underlying HDACdependent regulation of angiogenesis have also been investigated in primary endothelial cells. FK228 is a potent inhibitor of hypoxia-induced endothelial cell proliferation, migration and adhesion [88]. In vascular endothelial growth factor (VEGF)-induced angiogenesis in vivo models, TSA and SAHA inhibit angiogenesis and vasculogenesis - accompanied by suppression of VEGF receptors 1 and 2, and induction of the VEGF competitor semaphorin III [89]. Furthermore, valproic acid and TSA block endothelial cell nitric oxide signaling by suppressing expression of endothelial nitric oxide synthase [90,92].

Genetic studies have demonstrated that HDAC3 and HDAC7 play an important role in angiogenesis and the maintenance of vascular integrity. Elevated levels of HDAC3 are detected in the walls of blood vessels during embryogenesis in mice, and HDAC3 plays an essential role in VEGFinduced embryonic stem cell differentiation into endothelial cell lineages in vitro [93]. In mice lacking HDAC7 expression, endothelial cell-cell contacts are disrupted, leading to dilation and rupture of blood vessels, and embryonic lethality [94]. The silencing of HDAC7 in human endothelial cells results in cellular alterations in morphology, migration and capacity to form capillary tube-like structures. HDAC7 knockdown induces strong upregulation of platelet-derived growth factor B and its receptor, which is at least partially responsible for the inhibition of endothelial cell migration [95]. Together, these studies raise the possibility that targeting specific HDACs may be useful in preventing contributions of angiogenesis to inflammation and joint destruction in RA. 


\section{Chondrocytes}

Effects of HDACi on cartilage and collagen catabolism by chondrocytes may also contribute to protection of animals from joint destruction in experimental models of arthritis. Treatment of primary human chondrocytes with either TSA or phenylbutyrate inhibits gene and protein induction of matrix metalloproteinases and aggrecan-degrading enzymes (ADAMTS) induced by IL-1 $\beta$ and oncostatin M [96]. TSA and butyric acid also block nitric oxide, prostaglandin $\mathrm{E}_{2}$, and proteoglycan release in TNF $\alpha$-stimulated, IL-1 $\beta$-stimulated and IL-17-stimulated osteoarthritis chondrocytes or cartilage explants [97], indicating that inflammatory disease does not generally render chondrocytes insensitive to HDACi.

These initial studies together indicate that HDACi generally possess anti-inflammatory (or otherwise therapeutic) effects in vitro on many of the cell populations that contribute to synovitis and disease progression in RA. In terms of translational cell biology, it will be important to understand the effects of modulating expression and activity of specific HDACs in these cell populations. Additionally, more effort is needed in identifying appropriate biochemical and cellular biomarkers of compounds modulating HDAC activity, both in vitro and in therapeutic treatment of arthritis in animal models.

\section{Conclusions}

Temporal and balanced regulation of HAT and HDAC activity is required for an effective but self-limiting immune response. HAT activity allows transcription factor access to gene promoter regions, and modulates transcription factor stability, DNA binding and transcriptional activity. HDAC activity can subsequently modify transcription factor activity, prevent expression of proapoptotic genes, and eventually terminate transcription following deacetylation of histones.

While studies in human immune-mediated inflammatory diseases indicate that strategies aimed at decreasing HAT activity and restoring HDAC activity may benefit the treatment of RA, in vitro experimental data and animal arthritis models suggest promise for HDACi in the clinic. Are these strategies mutually exclusive? Integrating the available data into a testable model suggests not (Figure 3 ). If initial studies in RA synovial tissue can be extended to larger patient cohorts, and if depressed HDAC activity contributes to localized synovial inflammation, then we might predict that an enhanced ratio of HAT activity to HDAC activity may sensitize cells to inflammatory gene transcription via chromatin remodeling, may increase the DNA binding and activity of transcription factors, and may increase cellular resistance to GC treatment. Residual HDAC activity, however, would be sufficient to maintain transcription factor activity and prevent the targeting of genes that induce cell cycle arrest or apoptosis.

Restoration of HDAC activity could either decrease inflammatory gene transcription or enhance patient responses to GC treatment. If results from animal models of arthritis and in
Figure 3

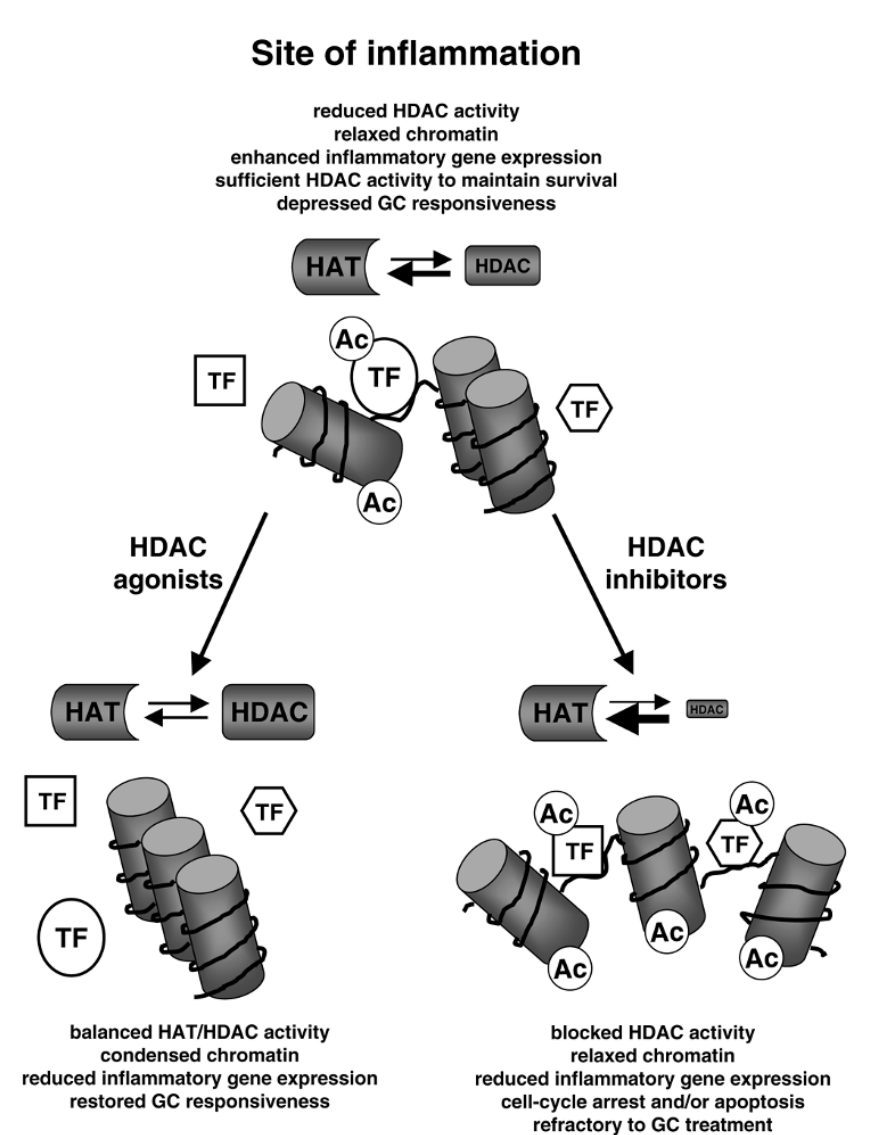

Potential pathological and therapeutic consequences of modulating histone deacetylase activity in rheumatoid arthritis. Depressed histone deacetylase (HDAC) activity relative to histone acetyl transferase (HAT) activity in rheumatoid arthritis (RA) synovial tissue might promote chromatin relaxation and activation of inflammatory transcription factors (TF). Moreover, depressed HDAC activity may decrease patient responsiveness to glucocorticoid (GC) treatment. The therapeutic application of HDAC agonists may decrease inflammation by promoting chromatin condensation and/or deacetylating TF at sites required for DNA binding. Additionally, patients may respond better to GC therapy. Therapeutic application of HDAC inhibitors might demonstrate clinical benefits by preventing deacetylation of TF at sites required for their activation, or inducing transcription of genes promoting cell cycle arrest or apoptosis. HDAC inhibitors, however, might render RA patients refractory to concomitant GC therapy. Ac, acetylation.

vitro studies of cells isolated from RA patients can be extended to RA synovial tissue, however, then residual HDAC activity may be critical for maintaining pathology. In this case, further depression of HDAC activity by HDACi might inhibit transcription factors required for inflammatory gene production, and instead may stimulate transcription of genes involved in cell cycle arrest and apoptosis.

Several pressing issues need to be addressed as we proceed with the preclinical evaluation of HAT and HDAC modulators in RA. Of immediate importance is determining 
whether or not there is a relationship between changes in synovial tissue HAT activity and HDAC activity with inflammation in RA - and if so, whether this relates to changes in acetylation of histone or nonhistone proteins. We also need to examine the effects of HDAC modulators on the activation and survival of specific RA synovial cell populations. By extension, biochemical and cellular biomarkers most relevant to modification of HAT activity or HDAC activity in RA remain to be identified. The determination of which HDACs are important for activation and survival of these cell populations will shed light on the molecular mechanisms of drug activity, and will indicate whether pan-HDACi or the targeting of specific HDACs will be most useful in the clinical setting. Finally, in eventually moving new compounds to the clinic, no studies have been performed examining the relationship between HAT and HDAC activity and RA patient responses to $\mathrm{GC}$ therapy. Given the intimate interaction of $\mathrm{GC}$ and acetylation in inflammatory lung diseases, this may be important in the future design of clinical trials.

Initial studies have certainly generated hope that modulating HDAC activity may provide a new therapeutic tool in the treatment of RA. But for the time being, until we more fully expose the contributions of protein acetylation and deacetylation to the pathobiology of RA, and the therapeutic potential of HDACi, it might be prudent to leave our HATs on.

\section{Additional files}

The following Additional file for this article is available online:

Additional file 1 is a Word file containing a document presenting supplementary materials and methods. See http:// arthritis-research.com/content/supplementary/ar2489-s1.doc

\section{Competing interests}

The authors declare that they have no competing interests.

\section{Acknowledgement}

The authors would like to express thanks to Dr Martijn Nolte (Division of Experimental Immunology, Academic Medical Center, University of Amsterdam) for critical reading of this manuscript.

\section{References}

1. Mclnnes IB, Schett G: Cytokines in the pathogenesis of rheumatoid arthritis. Nat Rev Immunol 2007, 7:429-442.

2. Tas SW, Remans PH, Reedquist KA, Tak PP: Signal transduction pathways and transcription factors as therapeutic targets in inflammatory disease: towards innovative antirheumatic therapy. Curr Pharm Des 2005, 11:581-611.

3. van der Helm-van Mil, Wesoly JZ, Huizinga TWJ: Understanding the genetic contribution to rheumatoid arthritis. Curr Opin Rheumatol 2005, 17:299-304.

4. Klose RJ, Bird AP: Genomic DNA methylation: the mark and its mediators. Trends Biochem Sci 2006, 31:89-97.

5. Huber LC, Stanczyk J, Jungel A, Gay S: Epigenetics in inflammatory rheumatic diseases. Arthritis Rheum 2007, 56:3523-3531.

6. Sanchez-Pernaute O, Ospelt C, Neidhart M, Gay S: Epigenetic clues to rheumatoid arthritis. $J$ Autoimmun 2008, 30:12-20.

7. Li B, Carey M, Workman JL: The role of chromatin during transcription. Cell 2007, 128:707-719.

8. Huber LC, Brock M, Hemmatazad H, Giger OT, Moritz F, Trenkmann M, Distler JH, Gay RE, Kolling C, Moch H, Michel BA,
Gay S, Distler O, Jungel A: Histone deacetylase/acetylase activity in total synovial tissue derived from rheumatoid arthritis and osteoarthritis patients. Arthritis Rheum 2007, 56:10871093.

9. Choo QY, Ho PC, Lin HS: Histone deacetylase inhibitors: new hope for rheumatoid arthritis? Curr Pharm Des 2008, 14:803820.

10. Urnov FD, Wolffe AP: Chromatin remodeling and transcriptional activation: the cast (in order of appearance). Oncogene 2001, 20:2991-3006.

11. Barnes PJ, Adcock IM, Ito K: Histone acetylation and deacetylation: importance in inflammatory lung diseases. Eur Respir $J$ 2005, 25:552-563.

12. Mujtaba S, Zeng L, Zhou MM: Structure and acetyl-lysine recognition of the bromodomain. Oncogene 2007, 26:55215527.

13. Saccani S, Natoli G: Dynamic changes in histone H3 Lys 9 methylation occurring at tightly regulated inducible inflammatory genes. Genes Dev 2002, 16:2219-2224.

14. Glozak MA, Sengupta N, Zhang X, Seto E: Acetylation and deacetylation of non-histone proteins. Gene 2005, 363:15-23.

15. Adcock IM, Cosio B, Tsaprouni L, Barnes PJ, Ito K: Redox regulation of histone deacetylases and glucocorticoid-mediated inhibition of the inflammatory response. Antioxid Redox Signal 2005, 7:144-152.

16. de Ruijter AJ, van Gennip AH, Caron HN, Kemp S, van Kuilenburg $A B$ : Histone deacetylases (HDACs): characterization of the classical HDAC family. Biochem J 2003, 370:737-749.

17. Dali-Youcef N, Lagouge M, Froelich S, Koehl C, Schoonjans K, Auwerx J: Sirtuins: the 'magnificent seven', function, metabolism and longevity. Ann Med 2007, 39:335-345.

18. Michan S, Sinclair D: Sirtuins in mammals: insights into their biological function. Biochem J 2007, 404:1-13.

19. Minucci S, Pelicci PG: Histone deacetylase inhibitors and the promise of epigenetic (and more) treatments for cancer. Nat Rev Cancer 2006, 6:38-51.

20. Khan N, Jeffers M, Kumar S, Hackett C, Boldog F, Khramtsov N, Qian X, Mills E, Berghs SC, Carey N, Finn PW, Collins LS, Tumber A, Ritchie JW, Jensen PB, Lichenstein HS, Sehested M: Determination of the class and isoform selectivity of smallmolecule histone deacetylase inhibitors. Biochem J 2008, 409:581-589.

21. Haggarty SJ, Koeller KM, Wong JC, Grozinger CM, Schreiber SL: Domain-selective small-molecule inhibitor of histone deacetylase 6 (HDAC6)-mediated tubulin deacetylation. Proc Natl Acad Sci U S A 2003, 100:4389-4394.

22. Neugebauer RC, Sippl W, Jung M: Inhibitors of NAD+ dependent histone deacetylases (sirtuins). Curr Pharm Des 2008, 14:562-573.

23. Yang SR, Wright J, Bauter M, Seweryniak K, Kode A, Rahman I: Sirtuin regulates cigarette smoke-induced proinflammatory mediator release via RelA/p65 NF-kappa B in macrophages in vitro and in rat lungs in vivo: implications for chronic inflammation and aging. Am J Physiol Lung Cell Mol Physiol 2007, 292:L567-L576.

24. Karagiannis TC, El Osta A: Will broad-spectrum histone deacetylase inhibitors be superseded by more specific compounds? Leukemia 2007, 21:61-65.

25. Mitsiades CS, Mitsiades NS, McMullan CJ, Poulaki V, Shringarpure R, Hideshima T, Akiyama M, Chauhan D, Munshi N, Gu X, Bailey C, Joseph M, Libermann TA, Richon VM, Marks PA, Anderson KC: Transcriptional signature of histone deacetylase inhibition in multiple myeloma: biological and clinical implications. Proc Natl Acad Sci U S A 2004, 101:540-545.

26. Peart MJ, Smyth GK, van Laar RK, Bowtell DD, Richon VM, Marks PA, Holloway AJ, Johnstone RW: Identification and functional significance of genes regulated by structurally different histone deacetylase inhibitors. Proc Natl Acad Sci U S A 2005, 102:3697-3702.

27. Chavez-Blanco A, Segura-Pacheco B, Perez-Cardenas E, TajaChayeb L, Cetina L, Candelaria M, Cantu D, Gonzalez-Fierro A, Garcia-Lopez P, ZambranoP, Perez-Plasencia C, Cabrera G, Trejo-Becerril C, Angeles E, Duenas-Gonzalez A: Histone acetylation and histone deacetylase activity of magnesium valproate in tumor and peripheral blood of patients with cervical cancer. A phase I study. Mol Cancer 2005, 4:22.

28. Kelly WK, O'Connor OA, Krug LM, Chiao JH, Heaney M, Curley T, 
MacGregore-Cortelli B, Tong W, Secrist JP, Schwartz L, Richardson S, Chu E, Olgac S, Marks PA, Scher H, Richon VM: Phase I study of an oral histone deacetylase inhibitor, suberoylanilide hydroxamic acid, in patients with advanced cancer. J Clin Oncol 2005, 23:3923-3931.

29. Glaser KB, Staver MJ, Waring JF, Stender J, Ulrich RG, Davidsen SK: Gene expression profiling of multiple histone deacetylase (HDAC) inhibitors: defining a common gene set produced by HDAC inhibition in T24 and MDA carcinoma cell lines. Mol Cancer Ther 2003, 2:151-163.

30. Joseph J, Mudduluru G, Antony S, Vashistha S, Ajitkumar P, Somasundaram K: Expression profiling of sodium butyrate (NaB)-treated cells: identification of regulation of genes related to cytokine signaling and cancer metastasis by $\mathrm{NaB}$. Oncogene 2004, 23:6304-6315.

31. Carta S, Tassi S, Semino C, Fossati G, Mascagni P, Dinarello CA, Rubartelli A: Histone deacetylase inhibitors prevent exocytosis of interleukin-1beta-containing secretory lysosomes: role of microtubules. Blood 2006, 108:1618-1626.

32. Gregoretti IV, Lee YM, Goodson HV: Molecular evolution of the histone deacetylase family: functional implications of phylogenetic analysis. J Mol Biol 2004, 338:17-31.

33. Chen L, Fischle W, Verdin E, Greene WC: Duration of nuclear NF-kappaB action regulated by reversible acetylation. Science 2001, 293:1653-1657.

34. Chen LF, Mu Y, Greene WC: Acetylation of RelA at discrete sites regulates distinct nuclear functions of NF-kB. EMBO $J$ 2002, 21:6539-6548.

35. Kiernan R, Bres V, Ng RW, Coudart MP, El Messaoudi S, Sardet C, Jin DY, Emiliani S, Benkirane M: Post-activation turn-off of NF-kappa B-dependent transcription is regulated by acetylation of p65. J Biol Chem 2003, 278:2758-2766.

36. Yeung F, Hoberg JE, Ramsey CS, Keller MD, Jones DR, Frye RA, Mayo MW: Modulation of NF- $\mathrm{kB}-$ dependent transcription and cell survival by the SIRT1 deacetylase. EMBO J 2004, 23: 2369-2380.

37. Coffer PJ, Burgering BM: Forkhead-box transcription factors and their role in the immune system. Nat Rev Immunol 2004, 4:889-899.

38. Calnan DR, Brunet A: The FoxO code. Oncogene 2008, 27: 2276-2288

39. Reedquist KA, Ludikhuize J, Tak PP: Phosphoinositide 3-kinase signalling and FoxO transcription factors in rheumatoid arthritis. Biochem Soc Trans 2006, 34:727-730.

40. Ludikhuize J, de Launay D, Groot D, Smeets TJ, Vinkenoog M, Sanders, ME, Tas SW, Tak PP, Reedquist KA: Inhibition of forkhead box class $O$ family member transcription factors in rheumatoid synovial tissue. Arthritis Rheum 2007, 56:21802191.

41. Matsuzaki $H$, Daitoku $H$, Hatta $M$, Aoyama $H$, Yoshimochi $K$, Fukamizu A: Acetylation of Foxo1 alters its DNA-binding ability and sensitivity to phosphorylation. Proc Natl Acad Sci U S A 2005, 102:11278-11283.

42. Lin L, Hron JD, Peng SL: Regulation of NF- $k B$, Th activation, and autoinflammation by the forkhead transcription factor Foxo3a. Immunity 2004, 21:203-213.

43. Jonsson H, Allen P, Peng SL: Inflammatory arthritis requires Foxo3a to prevent Fas ligand-induced neutrophil apoptosis. Nat Med 2005, 11:666-671.

44. Tak PP, Smeets TJ, Boyle DL, Kraan MC, Shi Y, Zhuang S, Zvaifler NJ, Breedveld FC, Firestein GS: p53 overexpression in synovial tissue from patients with early and longstanding rheumatoid arthritis compared with patients with reactive arthritis and osteoarthritis. Arthritis Rheum 1999, 42:948-953.

45. Yamanishi Y, Boyle DL, Rosengren S, Green DR, Zvaifler NJ, Firestein GS: Regional analysis of p53 mutations in rheumatoid arthritis synovium. Proc Natl Acad Sci U S A 2002, 99: 10025-10030.

46. Tak PP, Zvaifler NJ, Green DR, Firestein GS: Rheumatoid arthritis and p53: how oxidative stress might alter the course of inflammatory diseases. Immunol Today 2000, 21:78-82.

47. Lavin MF, Gueven N: The complexity of p53 stabilization and activation. Cell Death Differ 2006, 13:941-950.

48. Luo J, Nikolaev AY, Imai S, Chen D, Su F, Shiloh A, Guarente L, Gu W: Negative control of p53 by Sir2alpha promotes cell survival under stress. Cell 2001, 107:137-148.

49. Kasperkovitz PV, Verbeet NL, Smeets TJ, van Rietschoten JG,
Kraan MC, van der Pouw Kraan TC, Tak PP, Verweij CL: Activation of the STAT1 pathway in rheumatoid arthritis. Ann Rheum Dis 2004, 63:233-239.

50. Liu H, Ma Y, Cole SM, Zander C, Chen KH, Karras J, Pope RM: Serine phosphorylation of STAT3 is essential for Mcl-1 expression and macrophage survival. Blood 2003, 102:344352.

51. Klampfer L, Huang J, Swaby LA, Augenlicht L: Requirement of histone deacetylase activity for signaling by STAT1. J Biol Chem 2004, 279:30358-30368.

52. Leng $C$, Gries M, Ziegler J, Lokshin A, Mascagni $P$, Lentzsch $S$, Mapara MY: Reduction of graft-versus-host disease by histone deacetylase inhibitor suberonylanilide hydroxamic acid is associated with modulation of inflammatory cytokine milieu and involves inhibition of STAT1. Exp Hematol 2006, 34:776787.

53. Wang $R$, Cherukuri $P$, Luo J: Activation of Stat3 sequence-specific DNA binding and transcription by p300/CREB-binding protein-mediated acetylation. J Biol Chem 2005, 280:1152811534

54. Yuan ZL, Guan YJ, Chatterjee D, Chin YE: Stat3 dimerization regulated by reversible acetylation of a single lysine residue. Science 2005, 307:269-273.

55. Cosio BG, Mann B, Ito K, Jazrawi E, Barnes PJ, Chung KF, Adcock IM: Histone acetylase and deacetylase activity in alveolar macrophages and blood mononocytes in asthma. $\mathrm{Am} J$ Respir Crit Care Med 2004, 170:141-147.

56. Ito K, Caramori G, Lim S, Oates T, Chung KF, Barnes PJ, Adcock IM: Expression and activity of histone deacetylases in human asthmatic airways. Am J Respir Crit Care Med 2002, 166:392396.

57. Ito K, Ito M, Elliott WM, Cosio B, Caramori G, Kon OM, Barczyk A, Hayashi S, Adcock IM, Hogg JC, Barnes PJ: Decreased histone deacetylase activity in chronic obstructive pulmonary disease. N Engl J Med 2005, 352:1967-1976.

58. Rajendrasozhan S, Yang SR, Kinnula VL, Rahman I: SIRT1, an antiinflammatory and antiaging protein, is decreased in lungs of patients with chronic obstructive pulmonary disease. Am J Respir Crit Care Med 2008, 177:861-870.

59. Sequiera J, Boily G, Bazinet S, Saliba S, He X, Jardine K, Kennedy C, Staines W, Rousseaux C, Mueller R, McBurney MW: Sirt-1 null mice develop an autoimmune-like condition. Exp Cell Res 2008 , in press.

60. Smeets TJ, Barg EC, Kraan MC, Smith MD, Breedveld FC, Tak PP: Analysis of the cell infiltrate and expression of proinflammatory cytokines and matrix metalloproteinases in arthroscopic synovial biopsies: comparison with synovial samples from patients with end stage, destructive rheumatoid arthritis. Ann Rheum Dis 2003, 62:635-638.

61. Ito K, Barnes PJ, Adcock IM: Glucocorticoid receptor recruitment of histone deacetylase 2 inhibits interleukin- $1 \beta$-induced histone $\mathrm{H} 4$ acetylation on lysines 8 and 12. Mol Cell Biol 2000, 20:6891-6903.

62. Ito K, Yamamura S, Essilfie-Quaye S, Cosio B, Ito M, Barnes PJ, Adcock IM: Histone deacetylase 2-mediated deacetylation of the glucocorticoid receptor enables NF-kB suppression. J Exp Med 2006, 203:7-13.

63. Buttgereit F, Saag KG, Cutolo M, Da Silva JA, Bijlsma JW: The molecular basis for the effectiveness, toxicity, and resistance to glucocorticoids: focus on the treatment of rheumatoid arthritis. Scand J Rheumato/ 2005, 34:14-21.

64. Van Everdingen AA, Jacobs JW, Siewertsz van Reesema DR, Bijlsma JW: Low-dose prednisone therapy for patients with early active rheumatoid arthritis: clinical efficacy, diseasemodifying properties, and side effects: a randomized, doubleblind, placebo-controlled clinical trial. Ann Intern Med 2002, 136:1-12.

65. Tabe Y, Konopleva M, Contractor R, Munsell M, Schober WD, Jin L, Tsutsumi-Ishii Y, Nagaoka I, Igari J, Andreeff M: Up-regulation of MDR1 and induction of doxorubicin resistance by histone deacetylase inhibitor depsipeptide (FK228) and ATRA in acute promyelocytic leukemia cells. Blood 2006, 107:15461554

66. Xiao JJ, Foraker AB, Swaan PW, Liu S, Huang Y, Dai Z, Chen J, Sadee W, Byrd J, Marcucci G, Chan KK: Efflux of depsipeptide FK228 (FR901228, NSC-630176) is mediated by P-glycoprotein and multidrug resistance-associated protein 1. J Pharma- 
col Exp Ther 2005, 313:268-276.

67. Blanchard F, Chipoy C: Histone deacetylase inhibitors: new drugs for the treatment of inflammatory diseases? Drug Discov Today 2005, 10:197-204.

68. Choi JH, Oh SW, Kang MS, Kwon HJ, Oh GT, Kim DY: Trichostatin $A$ attenuates airway inflammation in mouse asthma model. Clin Exp Allergy 2005, 35:89-96.

69. Chung YL, Lee MY, Wang AJ, Yao LF: A therapeutic strategy uses histone deacetylase inhibitors to modulate the expression of genes involved in the pathogenesis of rheumatoid arthritis. Mol Ther 2003, 8:707-717.

70. Nakamura T, Kukita T, Shobuike T, Nagata K, Wu Z, Ogawa K, Hotokebuchi T, Kohashi O, Kukita A: Inhibition of histone deacetylase suppresses osteoclastogenesis and bone destruction by inducing IFN- $\beta$ production. $J$ Immunol 2005, 175:5809-5816.

71. Nishida K, Komiyama T, Miyazawa S, Shen ZN, Furumatsu T, Doi $H$, Yoshida A, Yamana J, Yamamura M, Ninomiya Y, Inoue H, Asahara $\mathrm{H}$ : Histone deacetylase inhibitor suppression of autoantibody-mediated arthritis in mice via regulation of p16INK4a and p21(WAF1/Cip1) expression. Arthritis Rheum 2004, 50:3365-3376.

72. Lin HS, Hu CY, Chan HY, Liew YY, Huang HP, Lepescheux L, Bastianelli E, Baron R, Rawadi G, Clement-Lacroix P: Antirheumatic activities of histone deacetylase (HDAC) inhibitors in vivo in collagen-induced arthritis in rodents. $\mathrm{Br} J$ Pharmacol 2007, 150:862-872.

73. Su RC, Becker AB, Kozyrskyj AL, Hayglass KT: Epigenetic regulation of established human type 1 versus type 2 cytokine responses. J Allergy Clin Immunol 2008, 121:57-63.

74. Mishra N, Brown DR, Olorenshaw IM, Kammer GM: Trichostatin A reverses skewed expression of CD154, interleukin-10, and interferon-gamma gene and protein expression in lupus $\mathrm{T}$ cells. Proc Natl Acad Sci U S A 2001, 98:2628-2633.

75. Leoni $F$, Zaliani A, Bertolini G, Porro G, Pagani P, Pozzi P, Dona G, Fossati G, Sozzani S, Azam T, Bufler P, Fantuzzi G, Goncharov I, Kim SH, Pomerantz BJ, Reznikov LL, SiegmundB, Dinarello CA, Mascagni $P$ : The antitumor histone deacetylase inhibitor suberoylanilide hydroxamic acid exhibits antiinflammatory properties via suppression of cytokines. Proc Natl Acad Sci U $S$ A 2002, 99:2995-3000.

76. Tao R, de Zoeten EF, Ozkaynak E, Chen C, Wang L, Porrett PM, Li B, Turka LA, Olson EN, Greene MI, Wells AD, Hancock WW: Deacetylase inhibition promotes the generation and function of regulatory T cells. Nat Med 2007, 13:1299-1307.

77. Rahman MM, Kukita A, Kukita T, Shobuike T, Nakamura T, Kohashi $O$ : Two histone deacetylase inhibitors, trichostatin $A$ and sodium butyrate, suppress differentiation into osteoclasts but not into macrophages. Blood 2003, 101:3451-3459.

78. Cosio BG, Tsaprouni L, Ito K, Jazrawi E, Adcock IM, Barnes PJ: Theophylline restores histone deacetylase activity and steroid responses in COPD macrophages. J Exp Med 2004, 200:689695.

79. Brogdon JL, Xu Y, Szabo SJ, An S, Buxton F, Cohen D, Huang Q: Histone deacetylase activities are required for innate immune cell control of Th1 but not Th2 effector cell function. Blood 2007, 109:1123-1130.

80. Jungel A, Baresova V, Ospelt C, Simmen BR, Michel BA, Gay RE, Gay S, Seemayer CA, Neidhart M: Trichostatin A sensitises rheumatoid arthritis synovial fibroblasts for TRAIL-induced apoptosis. Ann Rheum Dis 2006, 65:910-912.

81. Tomita K, Barnes PJ, Adcock IM: The effect of oxidative stress on histone acetylation and IL-8 release. Biochem Biophys Res Commun 2003, 301:572-577.

82. Huber LC, Distler JHW, Moritz F, Hemmatazad H, Hauser T, Michel BA, Gay RE, Matucci-Cerinic M, Gay S, Distler O, Juengel A: Trichostatin a prevents the accumulation of extracellular matrix in a mouse model of bleomycin-induced skin fibrosis. Arthritis Rheum 2007, 56:2755-2764.

83. Pap T, Distler O: Linking angiogenesis to bone destruction in arthritis. Arthritis Rheum 2005, 52:1346-1348.

84. Sasakawa $Y$, Naoe $Y$, Noto $T$, Inoue $T$, Sasakawa $T$, Matsuo $M$ Manda T, Mutoh S: Antitumor efficacy of FK228, a novel histone deacetylase inhibitor, depends on the effect on expression of anglogenesis factors. Biochem Pharmacol 2003, 66:897-906.

85. Sawa $H$, Murakami $H$, Kumagai M, Nakasato $M$, Yamauchi $S$, Mat- suyama N, Tamura Y, Satone A, Ide W, Hashimoto I, Kamada H: Histone deacetylase inhibitor, FK228, induces apoptosis and suppresses cell proliferation of human glioblastoma cells in vitro and in vivo. Acta Neuropatho/ 2004, 107:523-531.

86. Yang $\mathrm{QC}$, Zeng BF, Shi ZM, Dong Y, Jiang ZM, Huang J, Lv YM, Yang CX, Liu YW: Inhibition of hypoxia-induced angiogenesis by trichostatin A via suppression of HIF-1a activity in human osteosarcoma. J Exp Clin Cancer Res 2006, 25:593-599.

87. Qian DZ, Kachhap SK, Collis SJ, Verheul HMW, Carducci MA, Atadja P, Pili R: Class II histone deacetylases are associated with VHL-independent regulation of hypoxia-inducible factor 1 alpha. Cancer Res 2006, 66:8814-8821.

88. Kwon HJ, Kim MS, Kim MJ, Nakajima H, Kim KW: Histone deacetylase inhibitor FK228 inhibits tumor angiogenesis. Int $J$ Cancer 2002, 97:290-296.

89. Deroanne CF, Bonjean K, Servotte S, Devy L, Colige A, Clausse $\mathrm{N}$, Blacher S, Verdin E, Foidart JM, Nusgens BV, Castronovo V: Histone deacetylases inhibitors as anti-angiogenic agents altering vascular endothelial growth factor signaling. Oncogene 2002, 21:427-436.

90. Michaelis M, Michaelis UR, Fleming I, Suhan T, Cinatl J, Blaheta RA, Hoffmann K, Kotchetkov R, Busse R, Nau H, Cinatl J: Valproic acid inhibits angiogenesis in vitro and in vivo. Mol Pharmacol 2004, 65:520-527.

91. Jeong JW, Bae MK, Ahn MY, Kim SH, Sohn TK, Bae MH, Yoo MA, Song EJ, Lee KJ, Kim KW: Regulation and destabilization of HIF-1 alpha by ARD1-mediated acetylation. Cell 2002, 111: 709-720.

92. Rossig L, Huige L, Fisslthaler B, Urbich C, Fleming I, Forstermann $U$, Zeiher AM, Dimmeler S: Inhibitors of histone deacetylation downregulate the expression of endothelial nitric oxide synthase and compromise endothelial cell function in vasorelaxation and angiogenesis. Circ Res 2002, 91:837-844.

93. Zeng L, Xiao O, Margariti A, Zhang Z, Zampetaki A, Patel S, Capogrossi MC, Hu Y, Xu Q: HDAC3 is crucial in shear- and VEGF-induced stem cell differentiation toward endothelial cells. J Cell Biol 2006, 174:1059-1069.

94. Chang SR, Young BD, Li SJ, Qi XX, Richardson JA, Olson EN: Histone deacetylase 7 maintains vascular integrity by repressing matrix metalloproteinase 10 . Cell 2006, 126:321. 334.

95. Mottet D, Bellahcene A, Pirotte S, Waltregny D, Deroanne C, Lamour V, Lidereau R, Castronovo V: Histone deacetylase 7 silencing alters endothelial cell migration, a key step in angiogenesis. Circ Res 2007, 101:1237-1246.

96. Young DA, Lakey RL, Pennington CJ, Jones D, Kevorkian L, Edwards DR, Cawston TE, Clark IM: Histone deacetylase inhibitors modulate metalloproteinase gene expression in chondrocytes and block cartilage resorption. Arthritis Res Ther 2005, 7:R503-R512.

97. Chabane N, Zayed N, Afif H, Mfuna-Endam L, Benderdour M, Boileau C, Martel-Pelletier J, Pelletier JP, Duval N, Fahmi H: Histone deacetylase inhibitors suppress interleukin-1 $\beta$ induced nitric oxide and prostaglandin $E(2)$ production in human chondrocytes. Osteoarthr Cartil 2008, 16:1267-1274.

98. Arnett FC, Edworthy SM, Bloch DA, McShane DJ, Fries JF, Cooper NS, Healey LA, Kaplan SR, Liang MH, Luthra HS, Medsger TA Jr, Mitchell DM, Neustadt DH, Pinals RS, Schaller JG, Sharp JT, Wilder RL, Hunder GG: The American Rheumatism Association 1987 revised criteria for the classification of rheumatoid arthritis. Arthritis Rheum 1988, 31:315-324. 